\title{
Pharmacokinetics and Tissue Distribution of PLGA- PLL-PEG-TF Nanoparticles Loaded with Daunorubicin and Tetrandrine Following Intravenous Injection in the Rats Using LC-MS/MS
}

\author{
Yonglu Wang ${ }^{1 *}$, Yang $\mathrm{Li}^{1}$, Jiwei $\mathrm{Liu}^{1,2}$, Xueming $\mathrm{Li}^{1^{*}}$ \\ ${ }^{1}$ College of Pharmacy, Nanjing Tech University CHINA. \\ ${ }^{2}$ Nanjing Bestform Pharmaceutical Technology Co., Ltd CHINA.
}

\begin{abstract}
Objective: A sensitive, rapid and reliable LC-MS/MS method was developed for simultaneously determination of daunorubicin (DNR) and tetrandrine (Tet) in rat plasma and tissues. Methods: The pharmacokinetics and tissue distribution of DNR/Tet-PLGAPLL-PEG-NPs-Tf (D/T-PPP-NPs-Tf)， DNR/Tet-PLGA-PLL-PEG-NPs (D/T-PPP-NPs) and $\mathrm{DNR} /$ Tet $(\mathrm{D} / \mathrm{T})$ solution were compared following intravenous injection in the rats. Result: Compare to D/T solution, the parameters of DNR and Tet in D/T-PPP-NPs-Tf group presented significantly higher AUC $(p<0.01)$ and lower $V(p<0.05)$. Compared with $\mathrm{D} / \mathrm{T}$ solution, the distribution of DNR in groups of D/T-PPP-NPs and D/T-PPP-NPs-Tf were higher in liver $(p<0.01)$, lung $(p<0.05)$, fat $(p<0.05)$ and testicle $(p<0.05)$, and were lower in heart, spleen, kidney $(p<0.01)$, brain and intestine $(p<0.01)$. The distribution of Tet in D/T-PPP-NPs and D/T-PPP-NPs-Tf groups were higher in liver, brain and uterus $(p<0.05)$, and were lower in heart, spleen, lung, kidney and fat $(p<0.05)$ compared with D/T solution. Conclusion: The LC-MS/MS method was specific, sensitive, rapid and reliable for the simultaneously determination of DNR and Tet in rat plasma and tissues. Compared with D/T solution, D/T-PPP-NPs-Tf tended to stay in the blood after injection. The distribution of D/T-PPP-NPs and D/T-PPP-NPs-Tf were significantly changed.
\end{abstract}

Key words: Nanoparticles, Daunorubicin, Tetrandrine, Pharmacokinetics, Tissue Distribution.

\section{INTRODUCTION}

Daunorubicin has been proved to be an effective anti-tumor antibiotic, which has been widely used in clinic for the treatment of leukemia. ${ }^{1}$ However the clinical application of DNR has been highly restricted by MDR (multidrug resistance) and cumulative cardiotoxicity which is one of its serious side effects. ${ }^{2}$ Tetrandrine (Tet) is one kind of bisbenzylisoquinoline alkaloid which has nonselective calcium channel block effect and has shown strong MDR reverse effect. ${ }^{3-5}$ In order to increase the therapeutic effect and decrease the toxicity of DNR, a Nano drug delivery system encapsulated DNR and Tet simultaneously was designed in our previous studies. ${ }^{1-10}$ The Nano drug delivery system comprised of a multi-polymer composing PLGA, PLL and PEG which has been widely studied recently. ${ }^{1-12}$ The DNR and Tet were loaded with a doubleemulsion solvent evaporation method. ${ }^{6}$ Then Transferrin $(\mathrm{Tf})$ was conjuncted into the surface of the nanoparticles in attempt to get a better targeting antitumor effect. The results of viability tests showed that $\mathrm{D} / \mathrm{T}$ PPP-NPs-Tf presented stronger cytotoxicity on K562/ADR cells compared with $\mathrm{D} / \mathrm{T}$ solution. D/T-PPP-NPs-Tf also showed stronger anticancer effects on nude mice xenografts K562/A02 cells after injection
Submission Date: 26-05-2017; Revision Date: 06-07-2017; Accepted Date: 25-09-2017

DOI: 10.5530/ijper.52.1.5 Correspondence: Yonglu Wang; Xueming Li, No. 30, Puzhu south Road, Nanjing 211816, P. R. CHINA.

Phone no: +86 2558356766 Fax no: +86 2558356766 E-mail:wl_761107@163.com; xuemingli@njtech.edu.cn

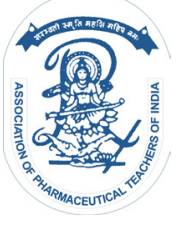

www.ijper.org 
compared with $\mathrm{D} / \mathrm{T}$ solution. ${ }^{6,7}$ Based on our previous work, Tf could significantly increase the drug concentration at the tumor tissue compared with D/T-PPPNPs group, which proved the active targeting antitumor effect of Tf. $^{7}$

The multi-polymer system of PLGA-PLL-PEG is quite new. There was no pharmacokinetic study about it. In this study, we want to investigate the pharmacokinetic characters of D/T-PPP-NPs-Tf in rats. In attempt to study the pharmacokinetics and tissue distribution of DNR and Tet in rats, a sensitive and reliable liquid chromatography with tandem mass spectrometry method (LC-MS/MS) was developed and validated for the quantification of DNR and Tet in rat plasma or tissues. ${ }^{13-16}$

\section{MATERIALS AND METHODS Materials}

Poly (lactic-co-glycolic acid) (PLGA; 50:50 lactic acid: glycolic acid; molecular weight $30 \mathrm{kDa}$ ) with carboxylic acid ends of was purchased from Evonik Industries (Frankfurt, Germany). Polyethylene glycol (PEG, Molecular Weight (MW) $4 \mathrm{kDa}$ ), dicyclohexyl carbodiimide (DCC), anhydrous dimethylformamide (DMF), N, N-carbonyldiimidazole (CDI) and 4-dimethylaminopyridine (DMAP) were purchased from the Aladdin Company (Shanghai, China). Ne-(Z)-L-lysine-N-carboxyanhydride (NCA) was purchased from the Hanhong Company (Shanghai, China). Daunorubicin(DNR), Doxrubicin(IS) and tetrandrine(Tet) were purchased from Jinan Huifengda Chemical Co., Ltd. (Jinan, China). Transferrin (Tf) was purchased from Sigma-Aldrich Co. (St Louis, MO, USA); HPLC grade acetonitrile was purchased from Wanqing Chemical Reagent Co., Ltd. (Nanjing, China). All other chemicals and reagents were of analytical grade. Sprague Dawley (SD) rats weighing 190-250 g, half male and half female, were obtained from Shanghai Jiesijie experimental animal Co. Ltd. The rats were acclimatized for ten days before experimentation, which were fed with a standard diet. All animal experiments were approved by the Animal Ethics Committee of Nanjing Tech University.

\section{Preparation}

ofDNR/Tet-PLGA-PLL-PEG-NPs-Tf(D/T-PPPNPs-Tf) and DNR/Tet-PLGA-PLL-PEG-NPs(D/TPPP-NPs)

D/T-PPP-NPs-Tf were prepared using the same procedure which had been reported in our previous study. ${ }^{1-6-8}$ The multipolymer comprising of PLGA, PLL and PEG (P-P-P) were synthesized firstly. Then DNR and Tet were loaded with a modified double-emulsion solvent evaporation method (D/T-PPP-NPs). Transferrin (Tf) was conjuncted into the surface of the nanoparticles (D/T-PPP-NPs-Tf) in attempt to get a better targeting antitumor effect. The samples were finally freeze-dried and stored at $4{ }^{\circ} \mathrm{C}$.

The average diameter, zeta potential and polydispersity index (PDI) of the D/T-PPP-NPs-Tf were evaluated using a Zetasizer $3000 \mathrm{HS}$ system (Malvern Instruments, UK). The amounts of DNR and Tet encapsulated in the NPs were determined by the LC-20ATvp HPLC (Shimadzu Corporation). Then the entrapment efficiency (EE) and drug-loading efficiency (DL) of DNR/Tet were calculated using methods which we have previously described. ${ }^{1,2,-6,7}$

\section{Analytical methods}

A Shimadzu HPLC system was used which equipped with a LC-20AD binary pump, a SIL-20AC auto sampler and a CTO-20AC column oven (Shimadzu Corporation, Kyoto, Japan). The Liquid chromatography was performed on a BDS HYPERSIL-C8 analytical column (100 $\mathrm{mm} \times 2.1 \mathrm{~mm}$, particle size $3 \mu \mathrm{m}$, Thermo Co., USA) at $40{ }^{\circ} \mathrm{C}$. The mobile phase consisted of acetonitrile and water containing $0.04 \%$ formic acid and $5 \mathrm{mmoL} \cdot \mathrm{L}-1$ ammonium acetate $(46: 54, \mathrm{v} / \mathrm{v})$. The flow rate was $0.2 \mathrm{~mL} / \mathrm{min}$. The detection was performed using an API 4000 Qtrap MS=MS system (Applied Biosystems, Foster City, CA, USA) with a Turbo Ion Spray inlet. The mass spectrometer was operated in the positive ionization mode at an ion source heater temperature of $450^{\circ} \mathrm{C}$. The multiple reaction monitoring (MRM) was used to monitor the transitions of the protonated molecular ions at mass-to-charge ratio $(\mathrm{m} / \mathrm{z}): 528 \rightarrow 363.1$ for DNR, $623.4 \rightarrow 381.1$ for Tet, and $544.3 \rightarrow 397.3$ for DOX. The optimized ion spray voltage was $5500 \mathrm{~V}$. Gas 1, gas 2 and curtain gas (nitrogen) were set at 50,50,10 psi, respectively. The declustering potential (DP) and collision energy (CE) were $60 \mathrm{~V}$ and $20 \mathrm{Ev}$ for DNR, $120 \mathrm{~V}$ and $59 \mathrm{Ev}$ for Tet, $68 \mathrm{~V}$ and $17 \mathrm{Ev}$ for DOX, respectively. The Chromatographic analysis using LC-MS/MS method was validated for the quantification of DNR and Tet in biological matrix. ${ }^{16-21}$

\section{Specificity}

The specificity of the LC-MS / MS method was assessed by comparing chromatograms of six different source blank biological samples with the corresponding spiked biological samples (plasmas or tissue homogenates) at LLOQ (Lowest Limit of Quantitation) level.

\section{Linearity and LLOQ}

The calibration curve was prepared by plotting the peak-area ratios of DNR or Tet to the IS (y-axis) versus 
the nominal concentration of DNR or Tet (x-axis) using a weighted linear regression. The LLOQ was defined as the lowest concentration of DNR or Tet in the standard curve with the signal-to-noise ratio was 10:1. The values could be detected with an acceptable precision and accuracy which were less than $20 \%$.

\section{Accuracy and precision}

The intra-day accuracy and precision were evaluated by analyzing the low, media and high Quality Control (QC) samples of biological samples in the same day. The inter day accuracy and precision were determined from the same samples in three consecutive days. The criteria for acceptability of the data included accuracy within $\pm 15 \%$ relative error (R.E.) from the nominal values and a precision of within $\pm 15 \%$ relative standard deviation (R.S.D.), except for LLOQ, whose accuracy and precision both within $\pm 20 \%$. The low, media and high concentrations for accuracy and precision assay were 4 , 40, $400 \mathrm{ng} \cdot \mathrm{mL}^{-1}$ for DNR and $0.8,20,300 \mathrm{ng} \cdot \mathrm{mL}^{-1}$ for Tet.

\section{Recovery and matrix effect}

The extraction recovery (ER) of DNR, Tet and DOX in biological samples at three concentrations were determined as the peak area ratios of the biological sample matrix spiked after extraction with a standard solution to the blank matrix spiked with the same standard solution. The matrix effect (ME) of extraction on DNR, Tet and DOX analysis was calculated by comparing the peak areas of extracted blank samples spiked with DNR, Tet and DOX at three concentrations with those of DNR, Tet and DOX spiked in mobile phase at the equivalent concentration. The three concentrations for ER and ME assay were $4,40,400 \mathrm{ng} \cdot \mathrm{mL}^{-1}$ for DNR and $0.8,20$, $300 \mathrm{ng} \cdot \mathrm{mL}^{-1}$ for Tet, while the single concentration of DOX was $100 \mathrm{ng} \cdot \mathrm{mL}^{-1}$.

\section{Stability}

The stability of DNR, Tet in rat plasma or tissue samples was determined using low, media and high QC samples which stored at room temperature for $24 \mathrm{~h}$, at $4{ }^{\circ} \mathrm{C}$ in auto sampler for $24 \mathrm{~h}$, after three-thaw cycle and stored at $-80{ }^{\circ} \mathrm{C}$ for 30 days.

\section{Pharmacokinetics study}

DNR and Tet were dissolved in mixture solution which consisted of Etoh, PEG400, Tween 80 and saline (5:5:2:88, v/v). Freeze-dried D/T-PPP-NPs and D/TPPP-NPs-Tf were dissolved in saline. Rats received i.v. injection of D/T-PPP-NPs, D/T-PPP-NPs-Tf or D/T solution (DNR $3 \mathrm{mg} / \mathrm{kg}$, Tet $2.5 \mathrm{mg} / \mathrm{kg}$ ) in groups $(\mathrm{n}=6)$ via the tail vein after an overnight fast $(12 \mathrm{~h})$ with free access to water. At predetermined time (5, 15, $30 \mathrm{~min}$ and $1,2,4,6,8,12,24,48,72 \mathrm{~h}$ ), the rats were anaesthetized with diethyl ether. The blood samples were collected from the retro-orbital sinus of rats, and then were transferred into heparinized $\left(10 \mu \mathrm{l}, 500 \mathrm{IU} \cdot \mathrm{mL}^{-1}\right)$ tubes and centrifuged at $3000 \times \mathrm{g}$ for $10 \mathrm{~min}$. The isolated plasma was stored at $-80^{\circ} \mathrm{C}$ for further analysis.

To determine the DNR and Tet concentration of blood samples, $10 \mu \mathrm{l}$ doxorubicin $\left(100 \mathrm{ng} \cdot \mathrm{mL}^{-1}\right)$ was added into $100 \mu \mathrm{l}$ plasma. Then the samples were vortexed for $30 \mathrm{~s}$ (VORTEX-5 vortex mixer, QILINBEIER, China). Then $1 \mathrm{~mL}$ diethyl ether was added followed by vortexing for another $5 \mathrm{~min}$. After centrifugation (Sigma Eppendorf Centrifuge 5810R, US) at $5000 \mathrm{rpm}$ for $10 \mathrm{~min}, 800 \mu \mathrm{l}$ of the supernatant was removed to clean test tubes and evaporated to dryness under vacuum (Speedvac concentrator, Thermo,USA) for $50 \mathrm{~min}$. The Residue was reconstituted in $100 \mu \mathrm{l}$ of mobile phase, and $8 \mu \mathrm{l}$ aliquots were injected into an analytical column for analysis.

\section{Tissue distribution study}

DNR and Tet in tissue samples were determined after i.v. injection with D/T-PPP-NPs, D/T-PPP-NPs-Tf or D/T solution (DNR $3 \mathrm{mg} / \mathrm{kg}$, Tet $2.5 \mathrm{mg} / \mathrm{kg}$ ) in groups $(\mathrm{n}=20)$ via the tail vein after an overnight fast $(12 \mathrm{~h})$ with free access to water. At predetermined time points ( 5 min and 1, 8, 24, $60 \mathrm{~h}$ ), four rats from each group were euthanized by cervical dislocation after blood collecting from the femoral artery. Then $0.2 \mathrm{~g}$ of selected organs such as liver, kidney, spleen, heart, lung, brain, muscle, fat, intestine and gonad (testis or ovary, uterus) were collected, washed, weighed and stored at $-80{ }^{\circ} \mathrm{C}$ for further analysis. All tissues samples were homogenized (Mixer Mill MM 400, Retsch, Germany) in $2 \mathrm{~mL}$ of saline, and then prepared using the method described above.

\section{Statistical analysis}

Pharmacokinetic analysis was estimated by DAS Version 2.1.1Software (Mathematical Pharmacology Professional Committee of China, Shanghai, China) using noncompartmental methods. The area under the plasma concentration time profiles (AUC), the mean residence time (MRT), total plasma clearance (CL), the elimination $\left(t_{1 / 2 \beta}\right)$ and distribution $\left(t_{1 / 2 \alpha}\right)$ half-life were calculated. Statistical significance on differences of pharmacokinetic parameters or tissue distribution samples was analyzed using SPSS (version 11.0 Student's t-test) and the statistical significance was defined by $\mathrm{P}<0.05$. 


\section{RESULTS AND DISCUSSION}

\section{Preparation of D/T-PPP-NPs-Tf}

The average diameter, zeta potential and polydispersity index (PDI) of the D/T-PPP-NPs-Tf were, 197.6 \pm 22 $\mathrm{nm},-20.54 \pm 0.13 \mathrm{mV}, 0.098 \pm 0.054$ respectively $(\mathrm{n}=3)$. The DL were $3.63 \pm 0.15 \%$ for DNR and $4.27 \pm 0.13 \%$ for Tet. The EE were $70.23 \pm 1.91 \%$ for DNR and $86.5 \pm 0.7 \%$ for Tet.

\section{Validation of the Method}

\section{Specificity}

Representative chromatographs of blank matrices, blank matrices spiked with DNR, Tet, IS, and biological samples collected after IV injection were shown in Figure 1, Figure 2 and Figure 3. The retention times of DNR, Tet, and IS were approximately 2.6, 3.1 and $2.2 \mathrm{~min}$, respectively. The chromatograms showed that a clear and excellent separation between DNR, Tet, and IS without detectable endogenous interfering peaks from biological sample nearby.

\section{Linearity and LLOQ}

The regression equation and correlation coefficient of DNR and Tet in biological samples were listed in Table 1, exhibiting good linearity. The assay was linear at concentration of $2-500 \mathrm{ng} \cdot \mathrm{mL}^{-1}$ for DNR and $0.5-400 \mathrm{ng} \cdot \mathrm{mL}^{-1}$ for Tet in all biological matrices. The LLOQ was $2 \mathrm{ng} \cdot \mathrm{mL}^{-1}(\mathrm{~S} / \mathrm{N}>10)$ for DNR and $0.5 \mathrm{ng} \cdot \mathrm{mL}^{-1}(\mathrm{~S} / \mathrm{N}>10)$ for Tet $0.5 \mathrm{ng} \cdot \mathrm{mL}^{-1}$. The accuracy and precision of LLOQ were less than $20 \%$ R.S.D. and R.E.

\section{Accuracy and precision}

The intra-day accuracies ranged from $2.60 \%$ to $4.51 \%$ for DNR, and from $3.44 \%$ to $6.59 \%$ for Tet in all biological matrices. The iner-day accuracies ranged from $2.85 \%$ to $3.88 \%$ for DNR, and from $2.08 \%$ to $5.37 \%$ for Tet. The results of precision for DNR and Tet were within $4.62 \%$. These results were all within $\pm 15 \%$ which was the acceptable range for biological samples analysis, which exhibited that this assay had good precision, reproducibility and accuracy.

\section{Recovery and matrix effect}

The results of extraction recovery and matrix effect for DNR and Tet in biological samples are summarized in Table 2. The extraction recoveries of DNR and Tet in biological samples were more than $70 \%$ at three QC concentrations, indicating reproducible and acceptable recoveries. The matrix effect of were DNR and Tet $93.2 \%$ to $105.7 \%$ in all biological matrices. These data indicated that there were no significant matrix effects for DNR and Tet in biological samples in the LC-MS / MS assay.

\section{Stability}

The accuracy ranged from 0.71 to $5.64 \%$ for DNR and -0.07 to $4.23 \%$ for Tet. These results showed that DNR and Tet demonstrated good stability in all biological matrices after being stored at room temperature for $24 \mathrm{~h}$, at $4{ }^{\circ} \mathrm{C}$ in the autosampler for $24 \mathrm{~h}$, after three-thaw cycle for 30 days.

Table 1: The regression equation and correlation coefficient of DNR and Tet in biological samples

\begin{tabular}{c|c|c|} 
Biological samples & \multicolumn{2}{|c|}{ The regression equation and correlation coefficient } \\
\cline { 2 - 3 } & DNR & Tet \\
\hline Plasma & $\mathrm{Y}=0.0863 \mathrm{X}-0.0223, \mathrm{R}=0.9981$ & $\mathrm{Y}=0.198 \mathrm{X}+0.0369, \mathrm{R}=0.9946$ \\
\hline Heart & $\mathrm{Y}=0.921+0.956 \mathrm{X}, \mathrm{R}=0.9957$ & $\mathrm{Y}=44.4+3.55 \mathrm{X}, \mathrm{R}=0.9937$ \\
\hline Liver & $\mathrm{Y}=0.805+1.63 \mathrm{X}, \mathrm{R}=0.9908$ & $\mathrm{Y}=1.34+6.74 \mathrm{X}, \mathrm{R}=0.9929$ \\
\hline Spleen & $\mathrm{Y}=5.9+1.91 \mathrm{X}, \mathrm{R}=0.9932$ & $\mathrm{Y}=343+16 \mathrm{X}, \mathrm{R}=0.9839$ \\
\hline Lung & $\mathrm{Y}=-3.52+1.91 \mathrm{X}, \mathrm{R}=0.9874$ & $\mathrm{Y}=107+7.43 \mathrm{X}, \mathrm{R}=0.9832$ \\
\hline Kidney & $\mathrm{Y}=0.981+1.63 \mathrm{X}, \mathrm{R}=0.9948$ & $\mathrm{Y}=25.9+6.85 \mathrm{X}, \mathrm{R}=0.9979$ \\
\hline Brain & $\mathrm{Y}=-0.125+0.338 \mathrm{X}, \mathrm{R}=0.9951$ & $\mathrm{Y}=0.0612+0.406 \mathrm{X}, \mathrm{R}=0.9889$ \\
\hline Muscle & $\mathrm{Y}=0.197+0.516 \mathrm{X}, \mathrm{R}=0.9962$ & $\mathrm{Y}=1.81+0.602 \mathrm{X}, \mathrm{R}=0.9947$ \\
\hline Fat & $\mathrm{Y}=0.263+0.563 \mathrm{X}, \mathrm{R}=0.9956$ & $\mathrm{Y}=57.7+1.65 \mathrm{X}, \mathrm{R}=0.9926$ \\
\hline Intestine & $\mathrm{Y}=3.98+0.561 \mathrm{X}, \mathrm{R}=0.9942$ & $\mathrm{Y}=15.2+1.34 \mathrm{X}, \mathrm{R}=0.9963$ \\
\hline Testis & $\mathrm{Y}=2.63+1.11 \mathrm{X}, \mathrm{R}=0.9960$ & $\mathrm{Y}=0.00634+1.58 \mathrm{X}, \mathrm{R}=0.9854$ \\
\hline Ovary & $\mathrm{Y}=-0.402+1.04 \mathrm{X}, \mathrm{R}=0.9953$ & $\mathrm{Y}=-0.0985+1.40 \mathrm{X}, \mathrm{R}=0.9882$ \\
\hline Uterus & $\mathrm{Y}=0.470+1.02 \mathrm{X}, \mathrm{R}=0.9974$ & \\
\hline & & \\
\hline
\end{tabular}




\section{Table 2: Extraction recovery and matrix effect of DNR and Tet in biological samples $(n=3)$}

\begin{tabular}{|c|c|c|c|c|}
\hline Drug & Biological sample & $\begin{array}{c}\text { Drug concentration/ } \\
\mathrm{ng} \cdot \mathrm{mL}^{-1}\end{array}$ & $\begin{array}{l}\text { Extraction } \\
\text { Recovery \% }\end{array}$ & Matrix effect $\%$ \\
\hline \multirow[t]{39}{*}{ DNR } & Plasma & 4 & 86.35 & 98.66 \\
\hline & & 40 & 87.81 & 103.26 \\
\hline & & 400 & 84.37 & 102.03 \\
\hline & Heart & 4 & 78.54 & 95.94 \\
\hline & & 40 & 81.91 & 93. 28 \\
\hline & & 400 & 72.62 & 101.78 \\
\hline & Liver & 4 & 74.83 & 102.46 \\
\hline & & 40 & 85.96 & 97.87 \\
\hline & & 400 & 84.89 & 95.32 \\
\hline & Spleen & 4 & 85.60 & 97.69 \\
\hline & & 40 & 74.67 & 103.57 \\
\hline & & 400 & 71.03 & 104.11 \\
\hline & Lung & 4 & 84.61 & 100.92 \\
\hline & & 40 & 72.38 & 101.61 \\
\hline & & 400 & 77.53 & 104.85 \\
\hline & Kidney & 4 & 78.18 & 101.41 \\
\hline & & 40 & 81.65 & 99.51 \\
\hline & & 400 & 81.54 & 98. 59 \\
\hline & Brain & 4 & 71.78 & 101.06 \\
\hline & & 40 & 73.76 & 93.46 \\
\hline & & 400 & 84.15 & 96.87 \\
\hline & Muscle & 4 & 81.69 & 93.43 \\
\hline & & 40 & 70.19 & 94.48 \\
\hline & & 400 & 75.87 & 96.55 \\
\hline & Fat & 4 & 77.69 & 99.18 \\
\hline & & 40 & 71.78 & 103.18 \\
\hline & & 400 & 81.39 & 104.74 \\
\hline & Intestine & 4 & 81.31 & 93.45 \\
\hline & & 40 & 79.57 & 104.52 \\
\hline & & 400 & 72.10 & 102.43 \\
\hline & Testis & 4 & 78.32 & 98.33 \\
\hline & & 40 & 73.69 & 104.76 \\
\hline & & 400 & 77.68 & 103.39 \\
\hline & Ovary & 4 & 71.72 & 97.93 \\
\hline & & 40 & 84.62 & 95.87 \\
\hline & & 400 & 70.46 & 101.41 \\
\hline & Uterus & 4 & 82.78 & 105.78 \\
\hline & & 40 & 79.58 & 94.54 \\
\hline & & 400 & 80.25 & 101.59 \\
\hline \multirow[t]{6}{*}{ Tet } & Plasma & 0.8 & 87.72 & 102.51 \\
\hline & & 20 & 88.73 & 102.35 \\
\hline & & 300 & 86.47 & 103.78 \\
\hline & Heart & 0.8 & 83.27 & 104.38 \\
\hline & & 20 & 70.02 & 95.64 \\
\hline & & 300 & 76.51 & 96.82 \\
\hline
\end{tabular}

Continued... 


\begin{tabular}{|c|c|c|c|c|}
\hline Drug & Biological sample & $\begin{array}{c}\text { Drug concentration/ } \\
\mathrm{ng} \cdot \mathrm{mL}^{-1}\end{array}$ & $\begin{array}{c}\text { Extraction } \\
\text { Recovery \% }\end{array}$ & Matrix effect $\%$ \\
\hline & Liver & 0.8 & 81.01 & 95.76 \\
\hline & & 20 & 72.81 & 96.41 \\
\hline & & 300 & 77.33 & 105.45 \\
\hline & Spleen & 0.8 & 79.13 & 102.17 \\
\hline & & 20 & 84.91 & 95.27 \\
\hline & & 300 & 70.97 & 96.81 \\
\hline & Lung & 0.8 & 81.19 & 104.34 \\
\hline & & 20 & 75.87 & 103.94 \\
\hline & & 300 & 70.31 & 102.47 \\
\hline & Kidney & 0.8 & 80.72 & 94.43 \\
\hline & & 20 & 80.22 & 97.31 \\
\hline & & 300 & 77.29 & 97.63 \\
\hline & Brain & 0.8 & 83.47 & 97.71 \\
\hline & & 20 & 82.99 & 98.52 \\
\hline & & 300 & 78.52 & 96.68 \\
\hline & Muscle & 0.8 & 72.98 & 102.16 \\
\hline & & 20 & 84.68 & 104.44 \\
\hline & & 300 & 79.71 & 98.59 \\
\hline & Fat & 0.8 & 75.82 & 103.78 \\
\hline & & 20 & 73.57 & 104.56 \\
\hline & & 300 & 82.48 & 104.48 \\
\hline & Intestine & 0.8 & 76.14 & 99.23 \\
\hline & & 20 & 81.76 & 103.32 \\
\hline & & 300 & 74.72 & 99.81 \\
\hline & Testis & 0.8 & 82.30 & 101.29 \\
\hline & & 20 & 72.54 & 97.88 \\
\hline & & 300 & 74.47 & 101.94 \\
\hline & Ovary & 0.8 & 71.84 & 105. 64 \\
\hline & & 20 & 83.03 & 102.92 \\
\hline & & 300 & 83.14 & 102.84 \\
\hline & Uterus & 0.8 & 83.70 & 104.56 \\
\hline & & 20 & 85.10 & 94.78 \\
\hline & & 300 & 75.48 & 104.27 \\
\hline
\end{tabular}

\section{Pharmacokinetics}

The plasma concentration-time profiles of DNR and Tet in different groups were shown in Figure 4 and the estimated pharmacokinetic parameters were shown in Table 3.

The data of plasma concentration time profile presented that the concentrations of DNR and Tet before $30 \mathrm{~min}$ in groups of $\mathrm{D} / \mathrm{T}-\mathrm{PPP}-\mathrm{NPs}$ and $\mathrm{D} / \mathrm{T}-\mathrm{PPP}-\mathrm{NPs}-\mathrm{Tf}$ NPs were significantly higher Compared with $\mathrm{D} / \mathrm{T}$ solution. That was why the AUC of DNR and Tet in D/T-PPP-NPs and D/T-PPP-NPs-Tf groups were significantly higher than $\mathrm{D} / \mathrm{T}$ solution. After $30 \mathrm{~min}$, the concentrations of DNR and Tet decreased to the same level of $\mathrm{D} / \mathrm{T}$ solution. As shown in Table 3, the parameters of DNR and Tet in D/T-PPP-NPs group presented no significant different compared with $\mathrm{D} / \mathrm{T}$ solution. Compare to $\mathrm{D} / \mathrm{T}$ solution, the parameters of DNR and Tet in D/T-PPP-NPs-Tf group presented a higher AUC and lower $\mathrm{V}(\mathrm{p}<0.05)$. These results indicated D/T-PPP-NPs-Tf tended to stay in the blood after injection compared to $\mathrm{D} / \mathrm{T}$ solution.

The in vivo characters of D/T-PPP-NPs-Tf were strongly depended on the nature of nanoparticle, such 


\begin{tabular}{|c|c|c|c|c|c|c|}
\hline \multirow{2}{*}{ Parameters } & \multicolumn{2}{|c|}{$\mathrm{D} / \mathrm{T}$ solution } & \multicolumn{2}{|c|}{ D/T-PPP-NPs } & \multicolumn{2}{|c|}{ D/T-PPP-NPs-Tf } \\
\hline & DNR & Tet & DNR & Tet & DNR & Tet \\
\hline $\mathrm{T}_{1 / 2} / \mathrm{h}$ & $9.04 \pm 5.53$ & $31.26 \pm 13.67$ & $5.62 \pm 2.16$ & $34.84 \pm 12.38$ & $6.93 \pm 3.75$ & $39.68 \pm 21.82$ \\
\hline $\mathrm{AUC}_{0-\mathrm{t}} / \mathrm{ng} \cdot \mathrm{mL}^{-1} \cdot \mathrm{h}^{-1}$ & $693.34 \pm 203.87$ & $932.48 \pm 538.49$ & $768.16 \pm 125.04$ & $1239.69 \pm 415.63^{*}$ & $1815.18 \pm 612.89^{* *}$ & $1544.84 \pm 722.40$ ** \\
\hline $\mathrm{AUC}_{0-\infty} / \mathrm{ng} \cdot \mathrm{mL}^{-1} \cdot \mathrm{h}^{-1}$ & $727.46 \pm 143.12$ & $1427.13 \pm 749.02$ & $803.50 \pm 324.42$ & $1963.11 \pm 1310.74$ * & $1883.60 \pm 608.82^{* *}$ & $1879.40 \pm 594.34^{*}$ \\
\hline $\mathrm{MRT}_{(0-\mathrm{t})} / \mathrm{h}$ & $8.22 \pm 1.27$ & $23.38 \pm 4.75$ & $4.87 \pm 1.64$ & $29.70 \pm 6.03$ & $5.69 \pm 2.70$ & $25.12 \pm 12.28$ \\
\hline $\mathrm{CL} / \mathrm{L} \cdot \mathrm{h}^{-1} \cdot \mathrm{kg}^{-1}$ & $53.18 \pm 21.63$ & $26.04 \pm 12.05$ & $42.58 \pm 25.77$ & $17.28 \pm 10.23$ & $38.18 \pm 21.98$ & $19.12 \pm 11.04$ \\
\hline $\mathrm{V} / \mathrm{L} \cdot \mathrm{kg}^{-1}$ & 594. $74 \pm 56.59$ & $905.38 \pm 68.27$ & $476.61 \pm 47.49$ & $818.28 \pm 191.72$ & $329.35 \pm 46.46$ * & $463.90 \pm 48.52^{*}$ \\
\hline
\end{tabular}

${ }^{*} p<0.05, * * p<0.01$ vs D/T solution

\begin{tabular}{|c|c|c|c|c|c|c|}
\hline \multirow[b]{2}{*}{ Drug } & \multirow[b]{2}{*}{ Tissue } & \multicolumn{3}{|c|}{$A \cup C_{0-12 h} /\left(n g \cdot g^{-1} \cdot h\right)$} & \multirow[b]{2}{*}{$r_{\mathrm{e} 1}$} & \multirow[b]{2}{*}{$r_{\mathrm{e} 2}$} \\
\hline & & $\mathrm{D} / \mathrm{T}$ solution & $\begin{array}{l}\text { (DNR/Tet)PLGA- } \\
\text { PLL-PEG }\end{array}$ & $\begin{array}{l}\text { (DNR/Tet)PLGA- } \\
\text { PLL-PEG-Tf }\end{array}$ & & \\
\hline & Heart & 29160.32 & $22273.93^{*}$ & 27747.84 & 0.76 & 0.95 \\
\hline & Liver & 13936.78 & $320173.41^{* *}$ & $349279.28^{* *}$ & 22.97 & 25.06 \\
\hline & Spleen & 170198.40 & $109210.14^{*}$ & 131789.33 & 0.64 & 0.77 \\
\hline & Lung & 63614.89 & $94862.88^{*}$ & $532813.75^{\star * \Delta}$ & 1.49 & 8.38 \\
\hline & Kidney & 44920.42 & $29900.95^{\star *}$ & $28525.35^{\star *}$ & 0.67 & 0.64 \\
\hline & Brain & 112.56 & $192.63^{*}$ & 130.13 & 1.71 & 1.16 \\
\hline \multirow[t]{12}{*}{ DNR } & Muscle & 5251.82 & 5782.59 & 7834.56 & 1.10 & 1.49 \\
\hline & Fat & 712.19 & $1677.86^{* *}$ & $1717.73^{\star *}$ & 2.36 & 2.41 \\
\hline & Intestine & 51151.50 & $3692.05^{\star *}$ & $3434.70^{* *}$ & 0.07 & 0.07 \\
\hline & Testicle & 139.66 & $1117.22^{\star *}$ & $875.25^{\star *}$ & 8.00 & 6.27 \\
\hline & Ovary & 9251.83 & $4455.95^{\star}$ & $14113.99^{* \Delta \Delta}$ & 0.48 & 1.53 \\
\hline & Uterus & 8893.24 & 8655.83 & 10005.85 & 0.97 & 1.13 \\
\hline & Heart & 118439.52 & $71059.67^{*}$ & $85003.30^{*}$ & 0.60 & 0.72 \\
\hline & Liver & 145428.67 & $573772.81^{* *}$ & $688867.5^{\star *}$ & 3.95 & 4.74 \\
\hline & Spleen & 1109640.01 & $790657.50^{*}$ & $808787.94^{*}$ & 0.71 & 0.73 \\
\hline & Lung & 1594564 & $364515.81^{* *}$ & $550250.31^{* * \Delta}$ & 0.23 & 0.35 \\
\hline & Kidney & 309396.16 & $88588.75^{\star *}$ & $65389.02^{* *}$ & 0.29 & 0.21 \\
\hline & Brain & 26.61 & $5455.66^{\star *}$ & $5653.54^{\star *}$ & 205.02 & 212.46 \\
\hline \multirow[t]{6}{*}{ Tet } & Muscle & 34056.1875 & $25881.46^{*}$ & $28603.75^{*}$ & 0.76 & 0.84 \\
\hline & Fat & 63475.83 & $21317.16^{* *}$ & $21744.24^{* *}$ & 0.34 & 0.34 \\
\hline & Intestine & 72626.52 & 69265.58 & 102719.09 & 0.95 & 1.41 \\
\hline & Testicle & 65139.84 & 61393.81 & 57942.11 & 0.94 & 0.89 \\
\hline & Ovary & 1407354.88 & 1275525 & $1850362.63^{\triangle}$ & 0.91 & 1.31 \\
\hline & Uterus & 705667.94 & $1014357.5^{\star *}$ & $945235.06^{*}$ & 1.44 & 1.34 \\
\hline
\end{tabular}

${ }^{*} p<0.05, * * p<0.01$ vs D/T solution; ${ }^{\Delta} p<0.05,{ }^{\Delta \Delta} p<0.05$ Vs D/T-PPP-NPs

$r_{\text {e1 }}=A \cup C_{\text {DNRTTE-PLGA.PLLPEG }} / A \cup C_{\text {DIT solution }}$

$r_{\text {e2 }}=A \cup C_{\text {DNR/Tet-PLGA-PLL-PEG-Tf }} / A \cup C_{\text {D/T solution }}$ 
- XIC of +MRM (4 pairs): 544.300/397.300 Da ID: AMS from Sample 5 (KB-3) of SET1. wiff (Turbo Spray)

Max. $26.7 \mathrm{cps}$.

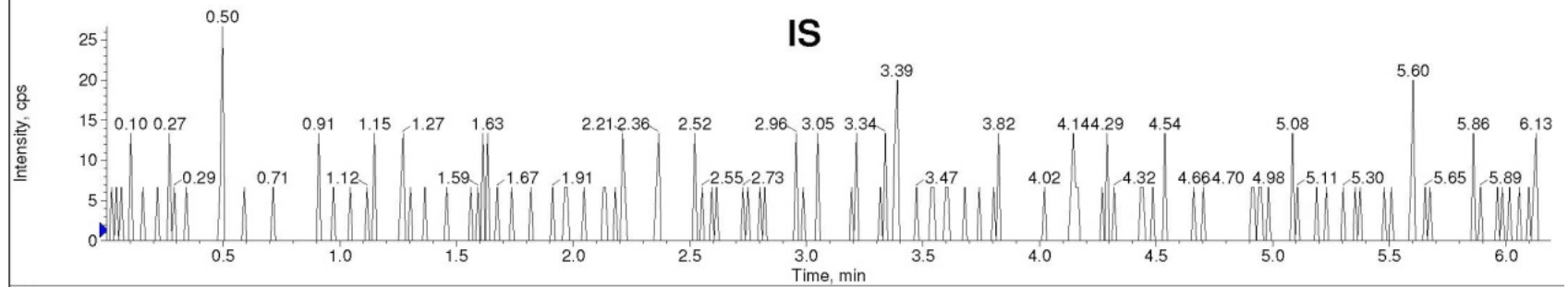

- XIC of +MRM (4 pairs): 528.000/321.000 Da ID: DNR from Sample 5 (KB-3) of SET1. wiff (Turbo Spray)

Max. $20.0 \mathrm{cps}$

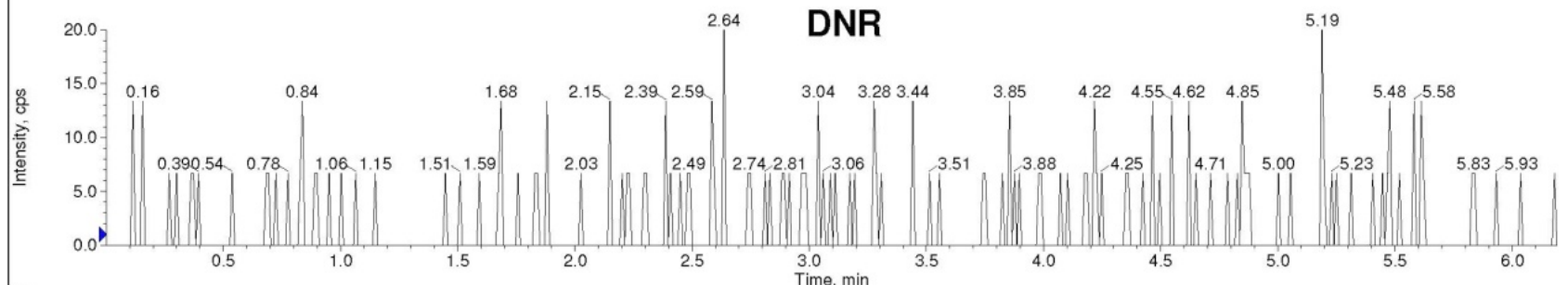

- XIC of +MRM (4 pairs): 623.400/381.100 Da ID: TET from Sample 5 (KB-3) of SET1, wiff (Turbo Spray)

Max. $33.3 \mathrm{cps}$.

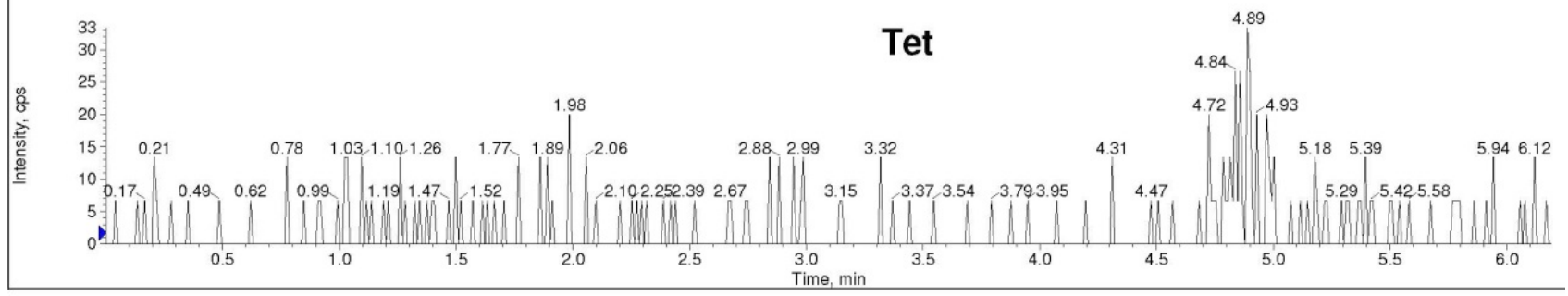

Figure 1: Representative MRM chromatograms of blank tissue (lung).

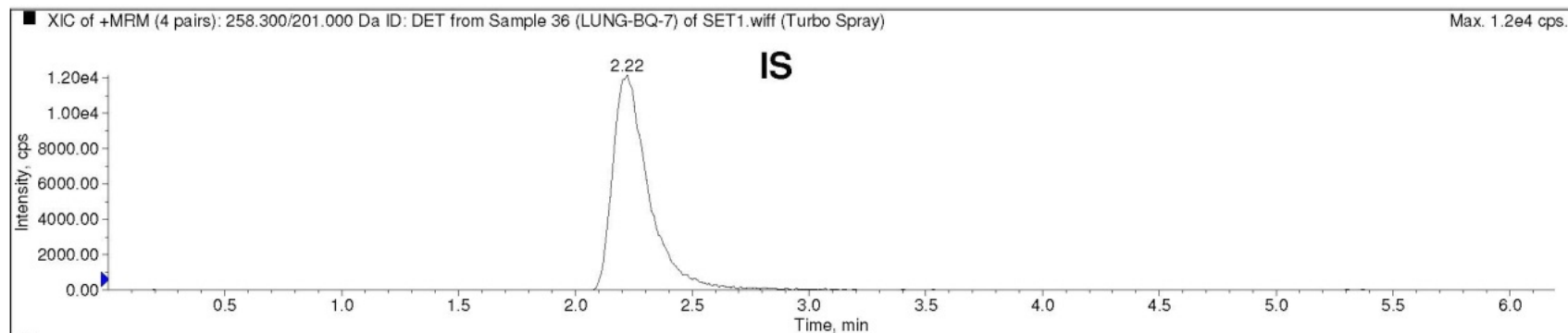

- XIC of +MRM (4 pairs): 528.000/321.000 Da ID: DNR from Sample 36 (LUNG-BQ-7) of SET1, wiff (Turbo Spray), Smoothed Max. $5394.4 \mathrm{cps}$.

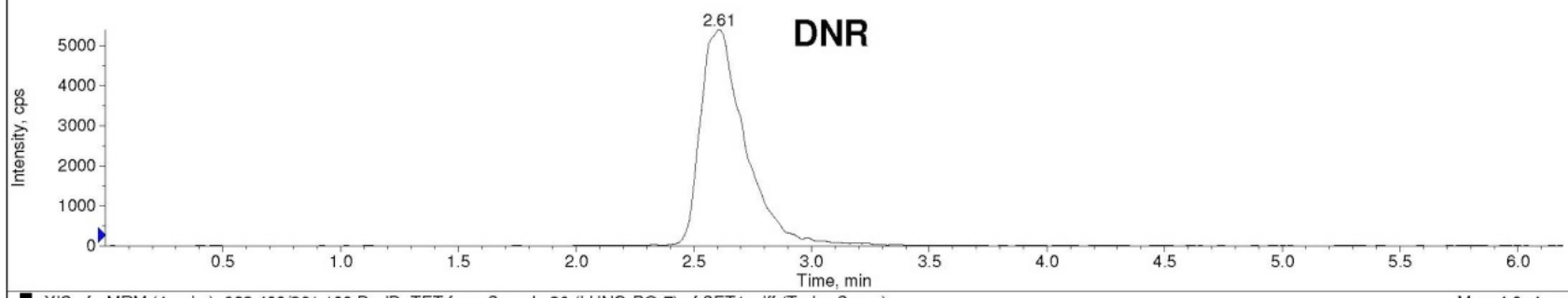

- XIC of +MRM (4 pairs): 623.400/381.100 Da ID: TET from Sample 36 (LUNG-BQ-7) of SET1.wiff (Turbo Spray)

Max. $4.9 \mathrm{e} 4 \mathrm{cps}$

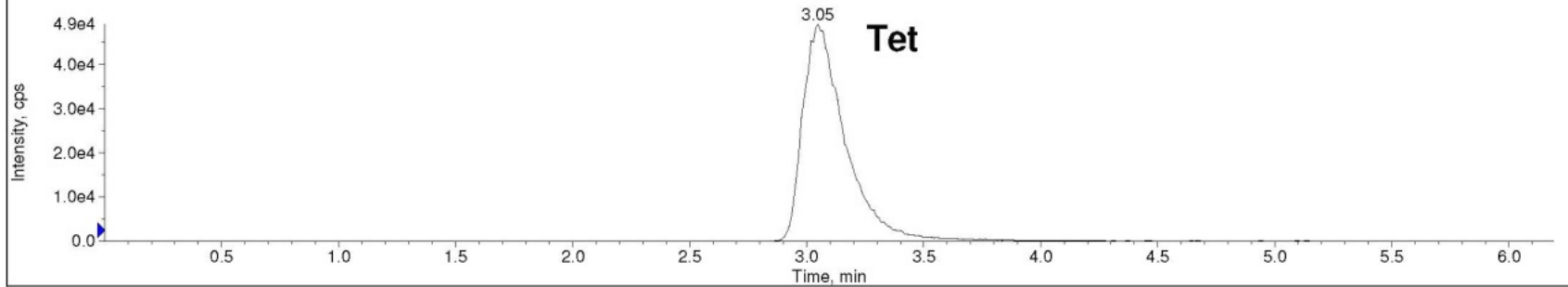

Figure 2: Representative MRM chromatograms of lung tissue spiked with DNR and Tet(DNR $206.4 \mathrm{ng} \cdot \mathrm{mL}^{-1}$, Tet 198.6ng $\cdot \mathrm{mL}^{-1}$ ). 


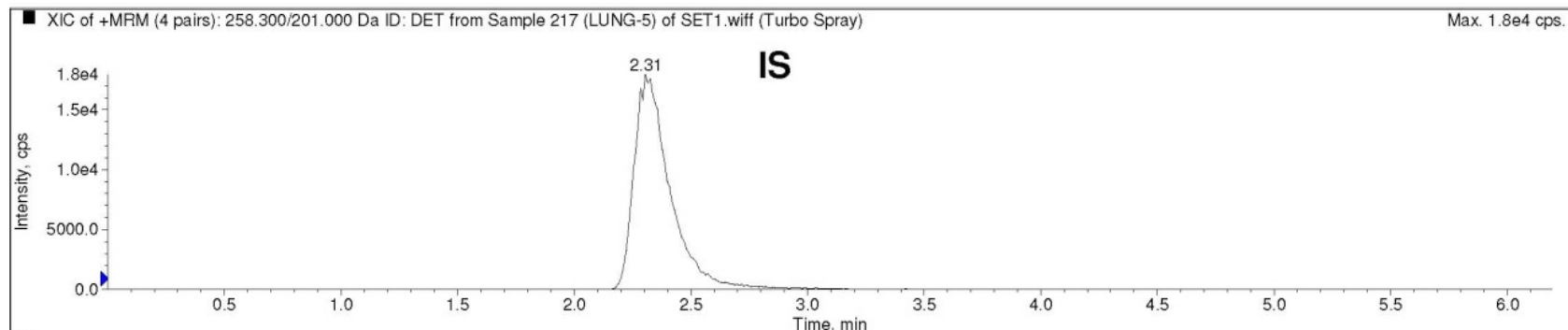

- XIC of +MRM (4 pairs): 528.000/321.000 Da ID: DNR from Sample 217 (LUNG-5) of SET1. wiff (Turbo Spray)

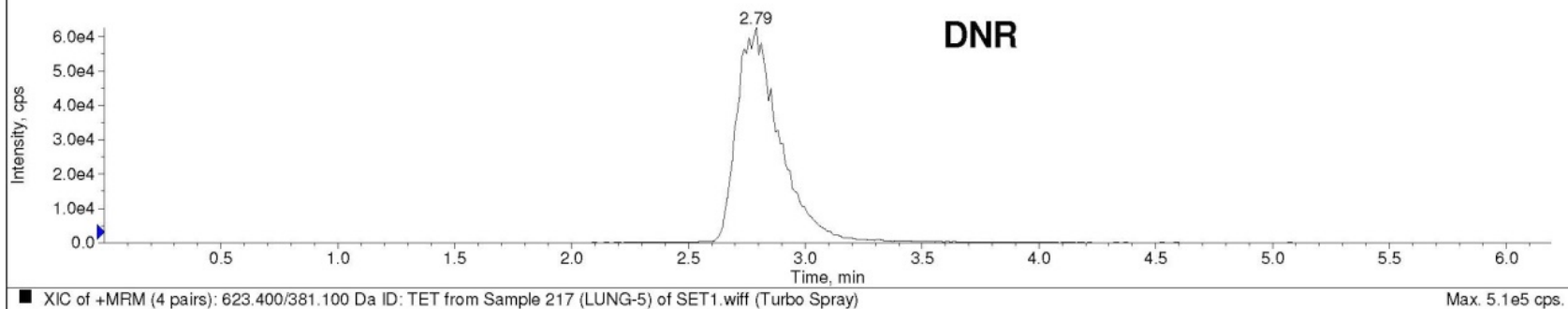

XIC of +MRM (4 pairs) 623 400/381.100 Da ID - TET from Sample 217 (LUNG-5) of SET1 wiff (Turbo Spray)

Tet

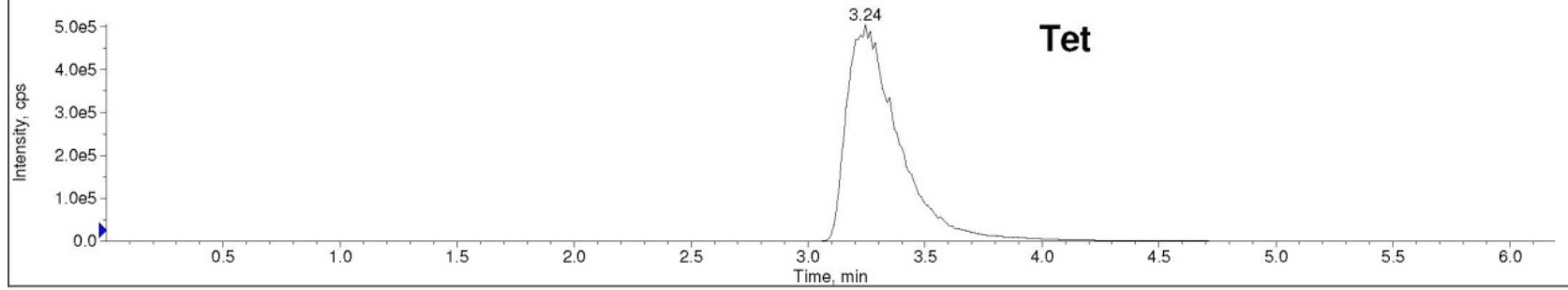

Figure 3: Representative MRM chromatograms of lung tissue of a rat lung tissue sample(3.275 $\mathrm{ng} \cdot \mathrm{mL}^{-1}$ )obtained $60 \mathrm{~h}$ after an intravenous administration of DNR and Tet solution.
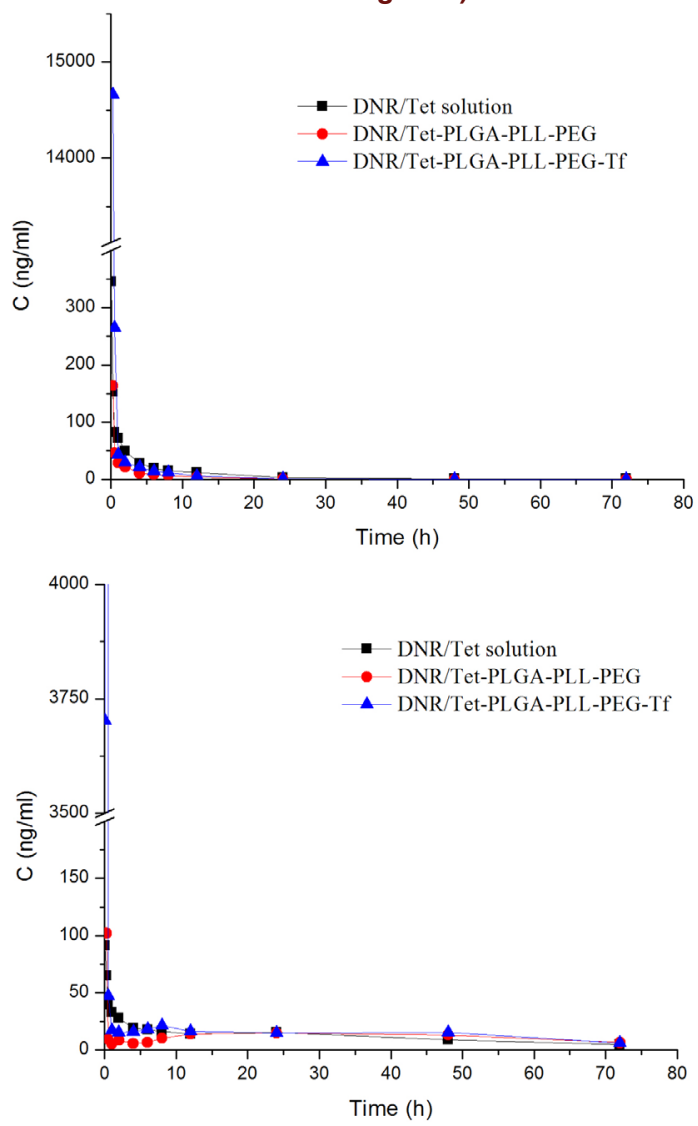

Figure 4: The Mean plasma concentration-time curves of DNR (A) and Tet (B) in D/T solution, D/T-PPP-NPs and D/TPPP-NPs-Tf

as the MW of PLGA, the particle size and the length of PEG chains ${ }^{22}$.

Based on our previous study, the results of in vitro release showed that $90 \%$ of free drugs were released in $3 \mathrm{~h}$, while only $50 \%$ to $60 \%$ drugs were released from the $\mathrm{D} / \mathrm{T}$ PPP-NPs-Tf in $24 \mathrm{~h}$. The plasma concentration-time profiles (Figure 4) and the estimated pharmacokinetic parameters (Table 3) indicated that D/T-PPP-NPs-Tf did not have long term release effect in vivo compared with free drugs. The similar pharmacokinetic behavior suggested that D/T-PPP-NPs-Tf dissolved rapidly in the blood compared to free drugs. Usually PEG was regarded the main moiety in multi polymer nanoparticles which has the potential to enhance the circulation time and reduce the clearance of NPs by thereticuloendothelial system. ${ }^{22}$ The clearance of the PEGylated moiety decreased significantly when one PEG chain with a molecular weight (MW) of $30 \mathrm{kDa}$ or a branched PEG chain with two $20 \mathrm{kDa}$ chains or several chains of 5 $\mathrm{kDa} .^{22,23}$ In our study, the MW of PEG was only $4000 \mathrm{Da}$ which was comparably small, so the pharmacokinetic parameters such of the NPs as MRT $\mathrm{T}_{(0-\mathrm{t})}$ and $\mathrm{T}_{1 / 2}$ had no different compared with free drugs. 

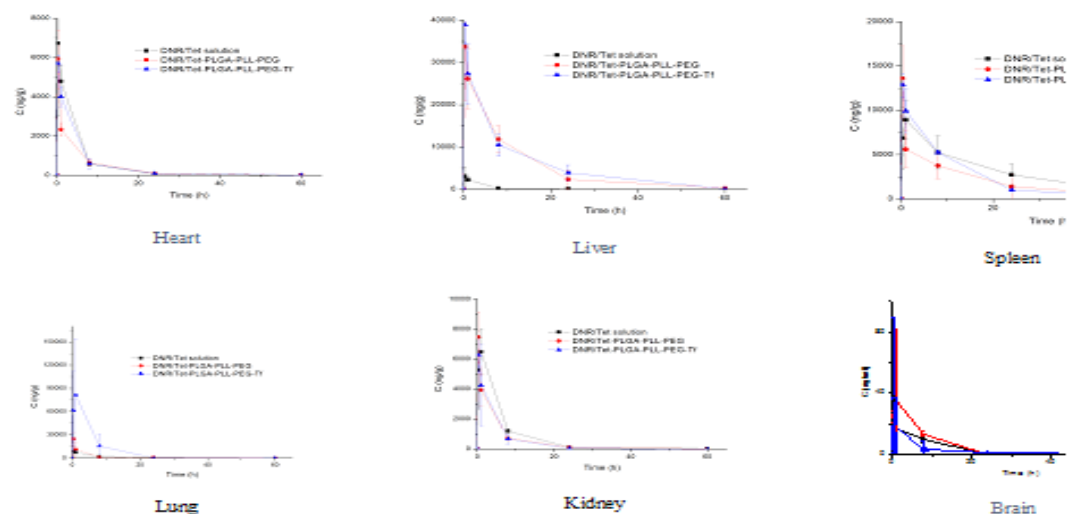

Spleen
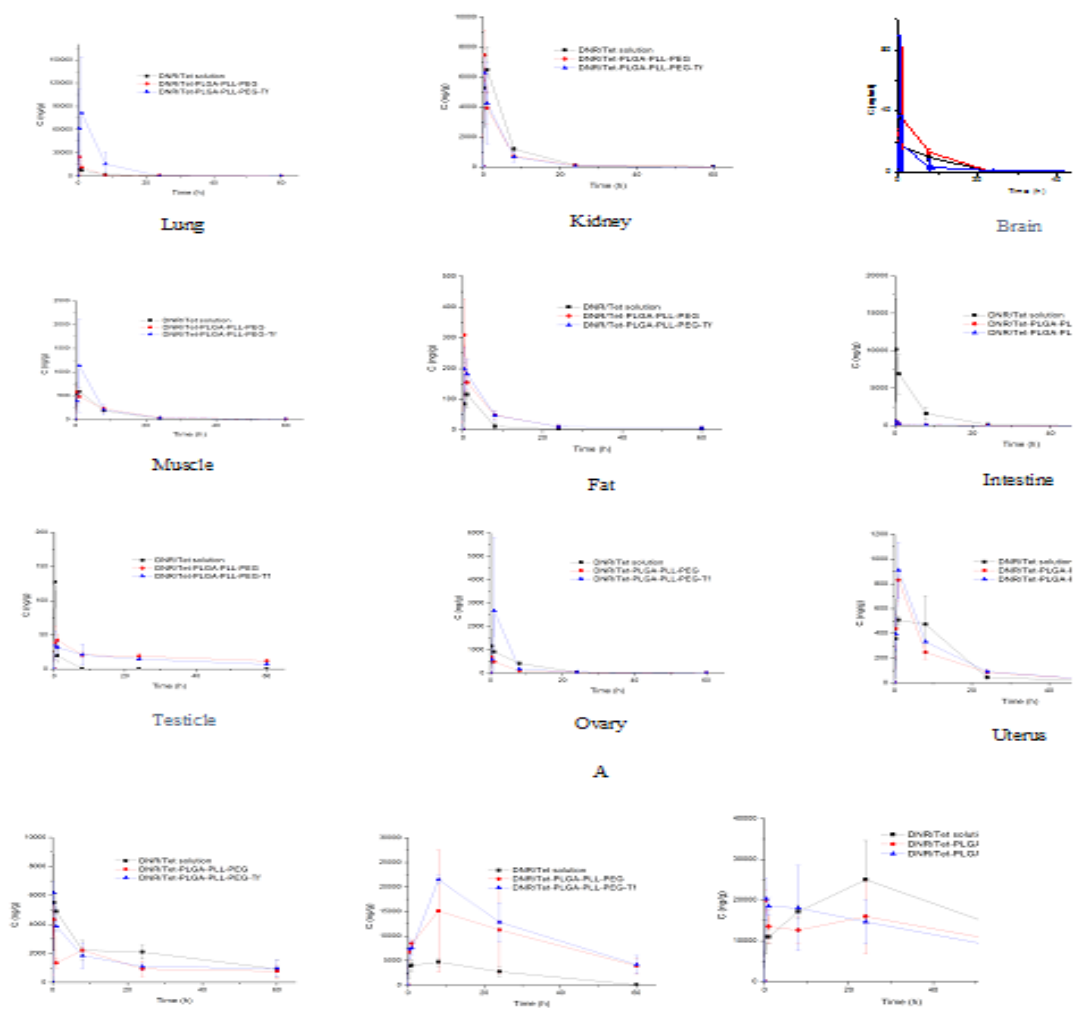

Heart

Liver

Spleen
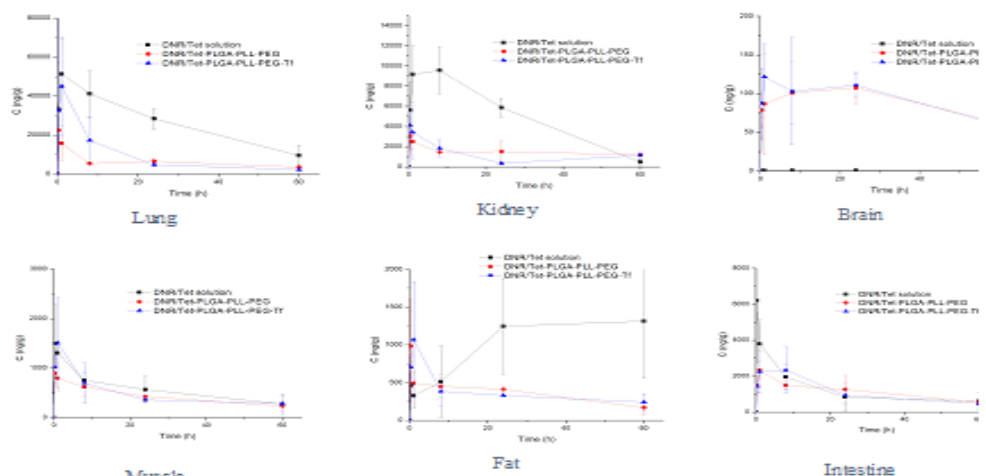

Muscle

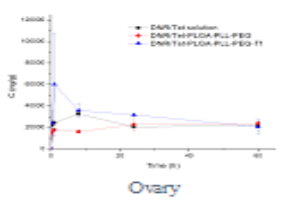

Intestine

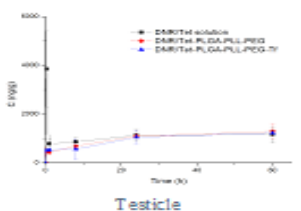

Figure 5: The Tissue distribution of DNR (A) and Tet $(B)$ in D/T solution, D/T-PPP-NPs and D/T-PPP-NPs-Tf 


\section{Tissue distribution}

The tissue distribution curves of DNR and Tet in different groups were shown in Figure 5 and the Re values in various tissues were shown in Table 4 . There were very few reports about the pharmacokinetics and tissue distribution of Tet. Our results of Tet solution were familiar with Professor Cheng's report. ${ }^{4}$ However, we gave more details about the tissue distribution of Tet in muscle, fat, intestine, and gonad.

Compared to $\mathrm{D} / \mathrm{T}$ solution, the distribution of $\mathrm{DNR}$ in groups of D/T-PPP-NPs and D/T-PPP-NPs-Tf were higher in liver $(p<0.01)$, lung $(p<0.05)$, fat $(p<0.01)$ and testicle $(\mathrm{p}<0.01)$, and were lower in heart, spleen, kidney $(\mathrm{p}<0.05)$ and intestine $(\mathrm{p}<0.01)$. The distribution of Tet in D/T-PPP-NPs and D/T-PPP-NPs-Tf groups were higher in liver $(\mathrm{p}<0.01)$, brain $(\mathrm{p}<0.01)$ and uterus $(p<0.05)$, and were lower in heart $(p<0.05)$, spleen $(p<0.05)$, lung $(p<0.01)$, kidney $(p<0.01)$ and fat $(\mathrm{p}<0.01)$ compared with $\mathrm{D} / \mathrm{T}$ solution. The distribution of DNR and Tet in D/T-PPP-NPs-Tf Group were similar with D/T-PPP-NPs, except the significantly higher concentration in lung $(\mathrm{p}<0.05)$ and ovary $(\mathrm{p}<0.05)$. D/T-PPP-NPs and DNR/Tet-PLGA-PLL-PEG-Tf presented targeting properties to liver. This result may be attributed to the uptake of nanoparticles by RES organs which have been widely reported. ${ }^{18-24}$ Concerning the gastrointestinal reactions and high cardiac toxicity of DNR, the lower distribution of DNR in heart and intestine was a great advantage for D/T-PPP-NPs and D/T-PPP-NPs-Tf.

\section{CONCLUSION}

The LC-MS/MS method was specific, sensitive, rapid and reliable for the simultaneously determination of DNR and Tet in rat plasma and tissues. This LC-MS/ MS method has been successfully used in the pharmacokinetic and tissue distribution research of DNR and Tet. D/T-PPP-NPs-Tf partly changed the pharmacokinetic parameter of DNR and Tet in rats. D/T-PPP-NPs-Tf tended to stay in the blood after injection compared to $\mathrm{D} / \mathrm{T}$ solution. Compared with $\mathrm{D} / \mathrm{T}$ solution, the distribution of D/T-PPP-NPs and D/T-PPP-NPs-Tf were significantly changed.

\section{ACKNOWLEDGEMENT}

This work was supported by the Study Abroad Scholarship of the Jiangsu Government, the Jiangsu Planned Projects for Postdoctoral Research Funds (No.1301012A) and the National Nature Science Foundation of China (No. 81170492).

\section{CONFLICT OF INTEREST}

The authors declare no conflict of interest.

\section{ABBREVIATION USED}

DNR: Daunorubicin; Tet: Tetrandrine; Tf: Transferrin; MDR: Multidrug resistance; PLGA: Poly (lacticco-glycolic acid); PEG: Polyethylene glycol; MW: Molecular Weight; DCC: dicyclohexyl carbodiimide; DMF: anhydrous dimethylformamide; CDI: N,N-carbonyldiimidazole; DMAP: 4-dimethylaminopyridine; IS: Doxrubicin; SD: Sprague Dawley; PDI: polydispersity index; EE: Entrapment efficiency; DL: Drugloading efficiency; DP: Declustering potential; CE: collision energy; LLOQ: Lowest Limit of Quantitation; QC: Quality Control; R.E.: relative error; R.S.D.: Relative standard deviation; ER: Extraction recovery; ME: Matrix effect; AUC: Area under the plasma concentration time profiles; MRT: the mean residence time; CL: total plasma clearance; $\mathbf{t} 1 / 2 \beta$ : The elimination half-life; $\mathrm{t} 1 / 2 \alpha$ :distribution half-life.

\section{REFERENCES}

1. Bao W, Liu R, Chen B. PLGA-PLL-PEG-Tf-based targeted nanoparticles drug delivery system enhance antitumor efficacy via intrinsic apoptosis pathway. Blood. 2015;126(23):5558-5558.

2. Chen B, Liu R, Liu P. Biocompatibility Assessment of DNR-Peg-PLL-PLGA Nanoparticles In vitro and In vivo. Blood. 2013;122(21):4920-4920.

3. Bhagya N, Chandrashekar KR. Tetrandrine-A molecule of wide bioactivity. Phytochemistry. 2016;125:5-13.

4. Li S, Ji Z, Zou M, Nie X, Shi Y, Cheng G. Preparation, characterization, pharmacokinetics and tissue distribution of solid lipid nanoparticles loaded with tetrandrine. AAPS PharmSciTech. 2011;12(3):1011-8.

5. Jiang XH, Yang JQ, Li N, Wang H, Zhou QX. The pharmacokinetical study of plant alkaloid tetrandrine with a simple HPLC method in rabbits. Fitoterapia. 2011;82(6):878-82.

6. Liu R, Wang Y, Li X. Synthesis and characterization of tumor-targeted copolymer nanocarrier modified by transferrin. Drug design, development and therapy. 2015;9:2705.

7. Guo L, Zhang H, Wang F. Targeted multidrug-resistance reversal in tumor based on PEG-PLL-PLGA polymer nano drug delivery system. International journal of nanomedicine. 2015;10:4535.

8. Guo L, Chen B, Liu R. Biocompatibility assessment of polyethylene glycolpoly I-lysine-poly lactic-co-glycolic acid nanoparticles in vitro and in vivo. Journal of nanoscience and nanotechnology. 2015;15(5):3710-9.

9. Yin P, Wang Y, Qiu Y. Bufalin-loaded mPEG-PLGA-PLL-cRGD nanoparticles: preparation, cellular uptake, tissue distribution, and anticancer activity. International journal of nanomedicine. 2012;7:3961.

10. Liu P, Qin L, Wang Q. cRGD-functionalized mPEG-PLGA-PLL nanoparticles for imaging and therapy of breast cancer. Biomaterials. 2012;33(28):6739-47.

11. Liu P, Sun $Y$, Wang $Q$, Sun $Y$, Li H, Duan Y. Intracellular trafficking and cellular uptake mechanism of mPEG-PLGA-PLL and mPEG-PLGAPLL-Gal nanoparticles for targeted delivery to hepatomas. Biomaterials. 2014;35(2):760-70.

12. Wang Y, Liu P, Qiu L. Toxicity and therapy of cisplatin-loaded EGF modified mPEG-PLGA-PLL nanoparticles for SKOV3 cancer in mice. Biomaterials. 2013;34(16):4068-77.

13. Song N, Zhang S, Li Q, Liu C. Establishment of a liquid chromatographic/ mass spectrometry method for quantification of tetrandrine in rat plasma 
and its application to pharmacokinetic study. Journal of Pharmaceutical and Biomedical Analysis. 2008;48(3):974-9.

14. Li D, Cao Z, Liao X, Yang P, Liu L. The development of a quantitative and qualitative method based on UHPLC-QTOF MS/MS for evaluation paclitaxeltetrandrine interaction and its application to a pharmacokinetic study. Talanta. 2016;160:256-67.

15. Caglar S, Morello R, Boos KS. Development and validation of an on-line multidimensional SPE-LC-MS/MS method for the quantitation of Tetrandrine in blood samples. Journal of Chromatography B. 2015;988:25-32.

16. Fan J, Guan L, Kou Z, Feng F, Zhang Y, Liu W. Determination of chrysotoxine in rat plasma by liquid chromatography-tandem mass spectrometry and its application to a rat pharmacokinetic study. Journal of Chromatography B. 2014;967:57-62.

17. Ren L, Ma B, Chen G. Quantitative determination of glaucocalyxin A in rat plasma by LC-MS/MS: Application to a preclinical pharmacokinetic study. Analytical Methods. 2013;5(18):4890-7.

18. Wang $\mathrm{Y}, \mathrm{Li} \mathrm{X}$, Wang $\mathrm{L}, \mathrm{Xu} \mathrm{Y}$, Cheng $\mathrm{X}$, Wei $\mathrm{P}$. Formulation and pharmacokinetic evaluation of a paclitaxel nanosuspension for intravenous delivery. International journal of nanomedicine. 2011;6:1497.
19. Wang Y, Wang L, Zhu X, Wang D, Li X. Choleretic Activity of Turmeric and its Active Ingredients. Journal of food science. 2016;81(7):H1800-6.

20. Ma B, Li X, Li J. Quantitative analysis of tenuifolin concentrations in rat plasma and tissue using LC MS/MS: Application to pharmacokinetic and tissue distribution study. Journal of pharmaceutical and biomedical analysis. 2014;88:191-200.

21. Liu YQ, He GH, Li HL. Plasma pharmacokinetics and tissue distribution study of roemerine in rats by liquid chromatography with tandem mass spectrometry (LC-MS/MS). Journal of Chromatography B. 2014;969:249-55.

22. Baumann A, Tuerck D, Prabhu S, Dickmann L, Sims J. Pharmacokinetics, metabolism and distribution of PEGs and PEGylated proteins: quo vadis? Drug Discovery Today. 2014;19(10):1623-31.

23. Caliceti P, Veronese FM. Pharmacokinetic and biodistribution properties of poly (ethylene glycol) protein conjugates. Advanced drug delivery reviews. 2003;55(10):1261-77.

24. Rabinow BE. Nanosuspensions in drug delivery. Nature Reviews Drug Discovery. 2004;3(9):785-96

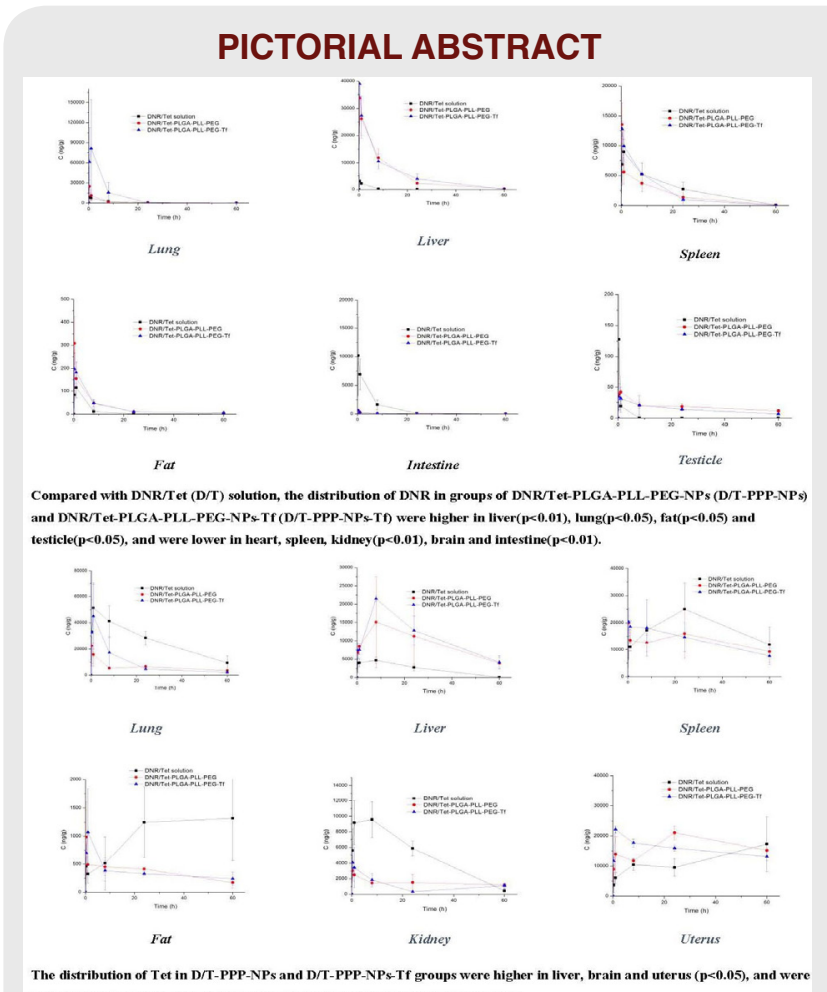

lower in heart, spleen, lung, kidney and fat((1) - 0.95) compared with $\mathrm{D} / \mathrm{T}$ solution.

\section{SUMMARY}

- A sensitive, rapid and reliable LC-MS/MS method was developed for simultaneously determination of daunorubicin (DNR) and tetrandrine (Tet) in rat plasma and tissues. The pharmacokinetics and tissue distribution of DNR/Tet-PLGA-PLL-PEG-NPs-Tf (D/T-PPP-NPs-Tf), DNR/Tet-PLGA-PLL-PEG-NPs (D/T-PPP-NPs) and DNR/Tet (D/T) solution were compared following intravenous injection in the rats. Compare to $D / T$ solution, the parameters of DNR and Tet in D/T-PPP-NPs-Tf group presented significantly higher $A \cup C(p<0.01)$ and lower $V(p<0.05)$. These results indicated that D/T-PPPNPs-Tf tended to stay in the blood after injection. Compared with $\mathrm{D} / \mathrm{T}$ solution, the distribution of DNR in groups of D/T-PPP-NPs and D/T-PPP-NPsTf were higher in liver $(p<0.01)$, lung $(p<0.05)$, fat $(p<0.05)$ and testicle $(p<0.05)$, and were lower in heart, spleen, kidney $(p<0.01)$, brain and intestine $(p<0.01)$. The distribution of Tet in D/TPPP-NPs and D/T-PPP-NPs-Tf groups were higher in liver, brain and uterus $(p<0.05)$, and were lower in heart, spleen, lung, kidney and fat $(p<0.05)$ compared with $\mathrm{D} / \mathrm{T}$ solution.

\section{About Authors}

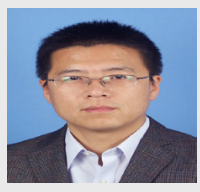

Dr. Yonglu Wang: Yonglu Wang is an associate professor of College of Pharmacy, Nanjing Tech University. He has 17 years of experience in biological pharmacy and pharmacokinetics study. His research interest is mainly in drug delivery systems.

Cite this article: Wang Y, Li Y, Liu J, Li X. Pharmacokinetics and Tissue Distribution of PLGA-PLL-PEG-TF Nanoparticles Loaded with Daunorubicin and Tetrandrine Following Intravenous Injection in the Rats Using LC-MS/MS. Indian J of Pharmaceutical Education and Research. 2018;52(1):42-53. 